\title{
Investigations for Supersonic Transports at Transonic and Supersonic Conditions
}

\author{
S. Melissa B. Rivers", Lewis R. Owens ${ }^{\dagger}$, and Richard A. Wahls ${ }^{\ddagger}$ \\ NASA Langley Research Center, Hampton, Virginia 23681
}

\begin{abstract}
Several computational studies were conducted as part of NASA's High Speed Research Program. Results of turbulence model comparisons from two studies on supersonic transport configurations performed during the NASA High-Speed Research program are given. The effects of grid topology and the representation of the actual wind tunnel model geometry are also investigated. Results are presented for both transonic conditions at Mach 0.90 and supersonic conditions at Mach 2.48. A feature of these two studies was the availability of higher Reynolds number wind tunnel data with which to compare the computational results. The transonic wind tunnel data was obtained in the National Transonic Facility at NASA Langley, and the supersonic data was obtained in the Boeing Polysonic Wind Tunnel. The computational data was acquired using a state of the art Navier-Stokes flow solver with a wide range of turbulence models implemented. The results show that the computed forces compare reasonably well with the experimental data, with the Baldwin-Lomax with Degani-Schiff modifications and the Baldwin-Barth models showing the best agreement for the transonic conditions and the Spalart-Allmaras model showing the best agreement for the supersonic conditions. The transonic results were more sensitive to the choice of turbulence model than were the supersonic results.
\end{abstract}

\section{Nomenclature}

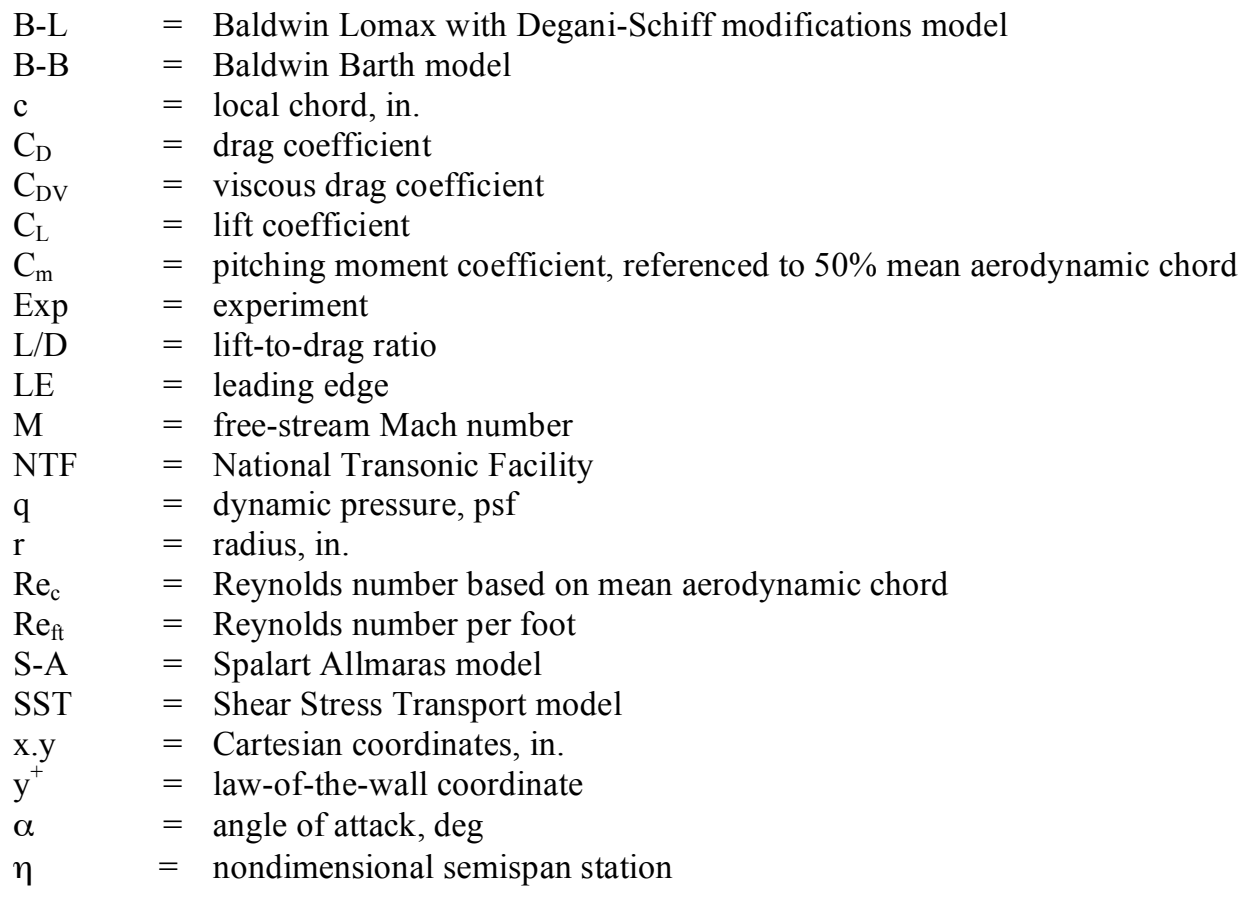

\footnotetext{
* Aerospace Engineer, Computational Aerodynamics Branch, Member AIAA

${ }^{\dagger}$ Aerospace Engineer, Flow Physics and Control Branch, Senior Member AIAA.

$\$$ Assistant Head, Configuration Aerodynamics Branch, Associate Fellow, AIAA.
} 


\section{Introduction}

This paper will present the results of several investigations conducted in support of NASA's High Speed Research (HSR) Program, Phase II, which was conducted from 1993-1999 ${ }^{1}$. The objective of this NASA sponsored, jointly executed program with US industry, was to develop critical high-risk airframe and propulsion technologies to enable industry development of an economically viable and environmentally acceptable second-generation high speed civil transport (HSCT). Aerodynamic performance was one of several broad airframe technology areas, and included tasks to address Configuration Aerodynamics for high-speed conditions and High-Lift Technology for take-off and landing. These elements encompassed not only the challenge of efficient supersonic cruise flight, but also the off-design challenges ${ }^{2}$ of efficient transonic cruise and acceleration and high-performance, quiet take-off and landing.

A configuration known as the Reference $\mathrm{H}$ was provided by Boeing and used as the basis for study including derivative design early in the program. The Reference $\mathrm{H}$ configuration represented a Mach 2.4, 300 passenger aircraft with a 5000 nautical mile range, and was characterized by its cranked-delta wing planform with a highly swept, blunt leading-edge (LE) inboard panel and a moderately swept, sharp LE outboard panel. The design of the outboard panel LE was driven by supersonic cruise considerations. During the course of the program, a second reference configuration was defined as the basis for further technology development; this configuration was known as the Technology Concept Airplane (TCA) and was defined based on results and lessons learned to that point in the program. The TCA, though different from the Reference $\mathrm{H}$, maintained a cranked-delta wing planform with a highly swept, blunt LE inboard panel and a moderately swept, sharp LE outboard panel. Similar to the earlier configuration, it was clear that the viability of a future HSCT would be significantly enhanced through improved low speed high-lift performance either through quieter engines and/or higher aerodynamic efficiency.

Increasing computer capacity and the development of efficient numerical methods enable the solution of the Navier-Stokes equations for practical aerodynamic simulations of advanced configurations such as a next generation supersonic transport. Of crucial importance to the usefulness of such simulations is the physical appropriateness and resulting accuracy of the turbulence model applied; the viability of a next generation supersonic transport is in part based on the ability to predict performance/drag to within one count at design cruise conditions, as well as to predict the onset and progression of separated flow that occurs over a range of angles-of-attack at off-design conditions. The search for a new or improved turbulence model that accurately predicts both attached and separated 3D flow fields is 
complicated by inherent limitations in the Computational Fluid Dynamics (CFD) codes that use them such as truncation error, grid density, the type of differencing scheme employed, and, for central-difference schemes, the amount of artificial dissipation added for numerical stability.

During the NASA High-Speed Research (HSR) program multiple studies were executed to assess the performance of various turbulence models. This paper gives the results of two investigations performed during the HSR program to assess and compare the ability of multiple turbulence models to accurately simulate flow at transonic and supersonic conditions over relevant supersonic transport configurations. This paper investigates the ability of four different turbulence models to accurately predict the transonic flow over the High-Speed Research/industry baseline configuration known as Reference $\mathrm{H}$. This configuration is an attached flow airplane that goes to separated flow at high angles-of-attack. The thin-layer Navier-Stokes solver CFL3D ${ }^{3}$ was run using the Baldwin-Lomax $^{4}$ with the Degani-Schiff modifications ${ }^{5}$, Baldwin-Barth ${ }^{6}$, Spalart-Allmaras ${ }^{7}$ and Menter's SST turbulence models $^{8}$ for the transonic study. The supersonic study also used CFL3D with the S-A, B-L, and B-B models, in addition to a preliminary version of the Gatski/Speziale $\mathrm{k}-\omega$ model $^{9}$. Each of these models is discussed in detail herein. No attempt was made to tune these turbulence models for the configuration being studied.

The effects of grid topology and the representation of the actual wind tunnel model geometry were also investigated. Computed forces and surface pressures compare reasonably well with the transonic experimental data for all four of the turbulence models. The equilibrium model of Baldwin-Lomax with the Degani-Schiff modifications showed the best agreement with the transonic computational pressures and with the force data at the high angle-of-attack and the one-equation Baldwin-Barth model showed the best agreement with the transonic force data at the lower angles-of-attack. The Spalart-Allmaras turbulence model showed the best agreement for the supersonic study. The sensitivity to turbulence model was larger in the transonic case than the supersonic case.

A feature of these studies was the availability of higher Reynolds number wind tunnel data from the National Transonic Facility (NTF) at NASA Langley and the Boeing Polysonic Wind Tunnel (PSWT) for comparison purposes. The uniqueness of the wind tunnel conditions available for comparison with state-of-the-art prediction tools provides an enduring benchmark relevant to a range of future supersonic aircraft, from business jets to large transport aircraft, both which fly at higher Reynolds numbers than attainable in conventional wind tunnels. 


\section{Experimental Approach}

\section{A. Transonic Conditions}

\section{Facility Description}

Transonic experimental data was acquired in the National Transonic Facility (NTF) at the NASA Langley Research Center. The $\mathrm{NTF}^{10}$ is a unique national facility (Figure 1) that enables tests of aircraft configurations at conditions ranging from subsonic to low supersonic speeds at Reynolds numbers up to full-scale flight values, depending on the aircraft type and size. The facility (Figure 2) is a fan-driven, closed-circuit, continuous-flow, pressurized wind tunnel capable of operating in either dry air at warm temperatures or nitrogen from warm to cryogenic temperatures. The test section is $8.2 \mathrm{ft}$ by $8.2 \mathrm{ft}$ in cross section and $25 \mathrm{ft}$ in length. The test section floor and ceiling are slotted (6 percent open), and the sidewalls are solid. Free-stream turbulence is damped by four screens and a 14.95:1 contraction ratio from the settling chamber to the test section. Fan-noise effects are minimized by an acoustic treatment both upstream and downstream of the fan. A detailed assessment of the dynamic flow quality in the NTF is reported in reference 11, and reconfirmed with more recent measurements shown in reference 12. The NTF is capable of an absolute pressure range from $15 \mathrm{psi}$ to $125 \mathrm{psi}$, a temperature range from $320^{\circ} \mathrm{F}$ to $150^{\circ} \mathrm{F}$, a Mach number range from 0.2 to 1.2 , and a maximum Reynolds number of $146 \times 10^{6} \mathrm{per} \mathrm{ft}$ at Mach 1. Typical tests use temperatures ranging from -250 to $120^{\circ} \mathrm{F}$. Further facility details can be found in reference 13 .

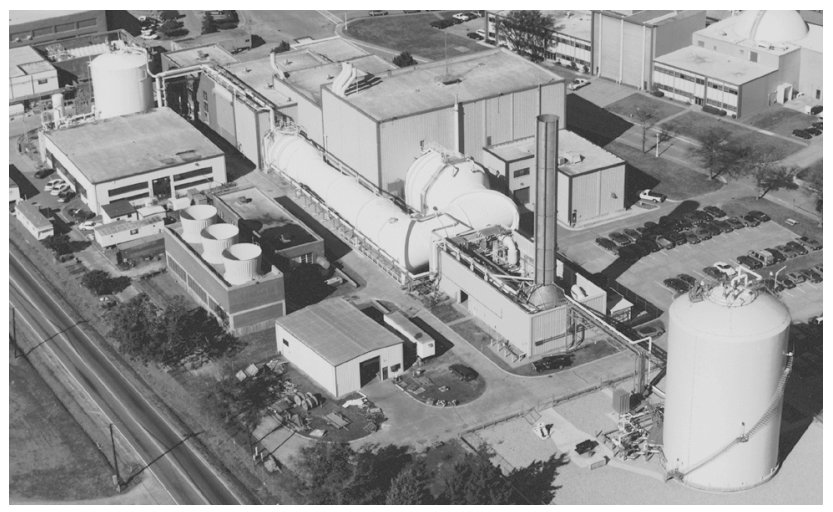

Figure 1. External view of the NTF. 


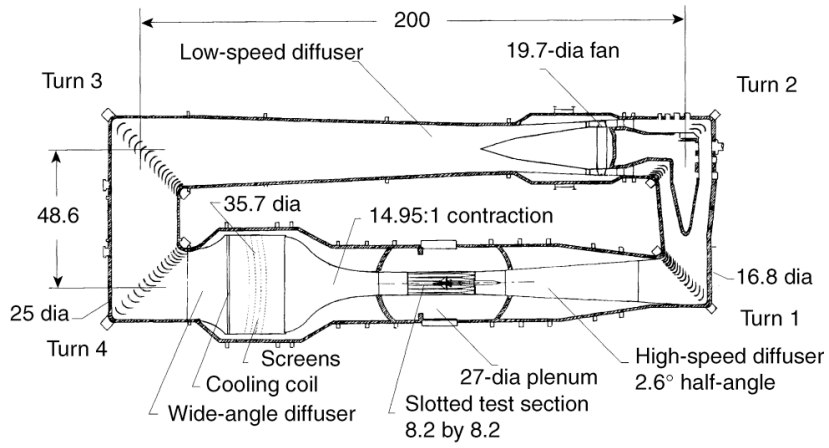

Figure 2. NTF circuit diagram (linear dimensions in $\mathbf{f t}$ ).

\section{Wind Tunnel Model}

Transonic experimental data was acquired using a truncated-aftbody model of a configuration known as the Reference H, which was designed by Boeing-Seattle for the HSR program. Figure 3 shows a planform drawing of the $2.2 \%$ scale model with wing pressure taps and reference locations noted. The model has a cranked-delta wing planform with an aspect ratio of 2.367 , a span of 34.23 inches, a mean aerodynamic chord of 22.71 inches, a reference area of $3.436 \mathrm{ft}^{2}$, and pitching moment data have been referenced to the 50 percent mean aerodynamic chord location. The leading edge sweep of the wing is $76 \mathrm{deg}$ inboard of $23 \%$ semispan, 68.50 deg from $23 \%$ to $52 \%$ semispan and $48 \mathrm{deg}$ outboard of $52 \%$ semispan. The leading edge is blunt inboard of $52 \%$ semispan and sharp outboard of $52 \%$ semispan. The model is shown in Figure 4 mounted in the NTF test section on a straight sting; the sting mounts to a 6-deg offset stub sting which in turn mounts to the facility arcsector resulting in a model angle-ofattack range from -4 to 24 degrees. Further details of the model are provided in references 14-18.

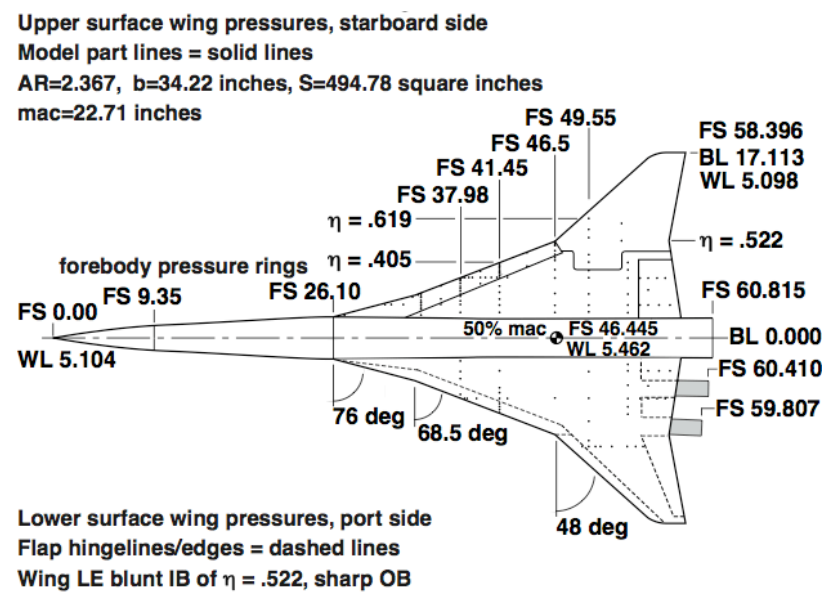

Figure 3. Model drawing with pressure locations (linear dimensions in inches). 


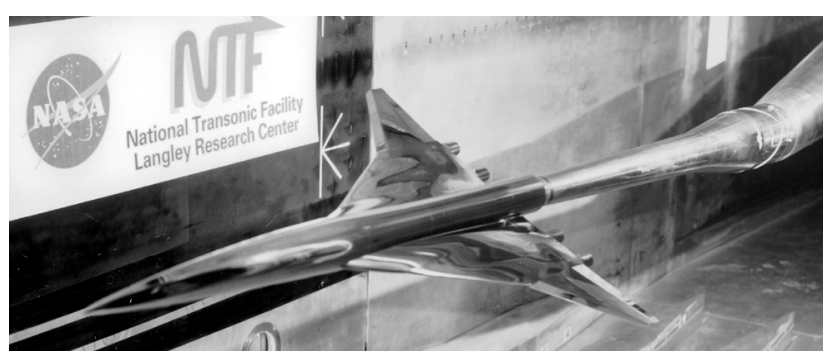

Figure 4. Reference H Model mounted in the NTF.

\section{Test Conditions and Data Quality}

The NTF is a cryogenic, pressure wind tunnel with independent control of pressure, temperature, and fan speed which allow Mach number, Reynolds number, and dynamic pressure to be varied independently. The wind tunnel tests of this model included a variety of configuration, Mach, Reynolds number, and dynamic pressure combinations. Flow conditions used for comparison herein are Mach 0.90, Reynolds number based on the mean aerodynamic chord of 30 million, and a dynamic pressure of $1005 \mathrm{psf}$ for the wing/body (nacelles off) configuration with all flaps set to zero degrees.

Standard balance, angle-of-attack, and tunnel parameter corrections have been applied. Wall and model support interference effects have not been accounted for in the data; these effects were minimized through model sizing, particularly for conditions below Mach 0.96 . The observed variability in the lift, drag, and pitching-moment coefficients was $\pm 0.002, \pm 0.0002$, and \pm 0.0003 , respectively. Reference 15 provides further discussion of data quality.

The significance of the 30 million Reynolds number test condition for this computational study is the naturally occurring fully turbulent flow observed in the experiment ${ }^{15}$. This reduces uncertainty in the assessment of the turbulence models in two ways: 1) no influence of roughness elements required to force transition, and 2) fully turbulent calculations from the leading edge are appropriate.

\section{B. Supersonic Conditions}

\section{Facility Description}

Supersonic experimental data was acquired in the Boeing (formerly McDonnell Douglas) Polysonic Wind Tunnel (PSWT) located in St. Louis, MO. The facility has the highest supersonic Reynolds number capability in the US. The PSWT is an intermittent pressure-to-atmosphere blowdown tunnel with two 4 by 4 by $6 \mathrm{ft}$ long test sections; one test section is for supersonic testing, the other for subsonic/transonic testing, and together enable a Mach number range from 0.3 to 5.5. In the supersonic configuration, start-up loads are reduced through the use of 
downstream ejectors. At the time of the test, the PSWT was not calibrated for Mach 2.4 (HSR program nominal cruise), but was calibrated at Mach 2.48. For the purposes of this investigation, this difference is not significant. A key characteristic of this facility is its high-pressure capability that in turn enables the high Reynolds number capability; the maximum Reynolds number of the facility at Mach 2.48 was not attainable due to model load/sting divergence limitations at high dynamic pressure.

\section{Wind Tunnel Model}

Supersonic experimental data was acquired using a 1.675\% scale model of the Boeing-Long Beach baseline arrow wing configuration used in the HSR program and designated M2.4-7A. A planform drawing is shown in Figure 5. The wing planform incorporates a leading-edge break at $70 \%$ semi-span and a trailing edge break at $30 \%$ semi-span; the planform in these regions has been smoothly faired. The leading-edge sweep is 71 deg inboard and $61.5 \mathrm{deg}$ outboard. The aspect ratio is 1.84 , and at model scale the reference area, mean aerodynamic chord and wingspan are $2.511 \mathrm{ft}^{2}, 18.886 \mathrm{in}$., and $2.149 \mathrm{ft}$, respectively. The body length is $4.395 \mathrm{ft}$.

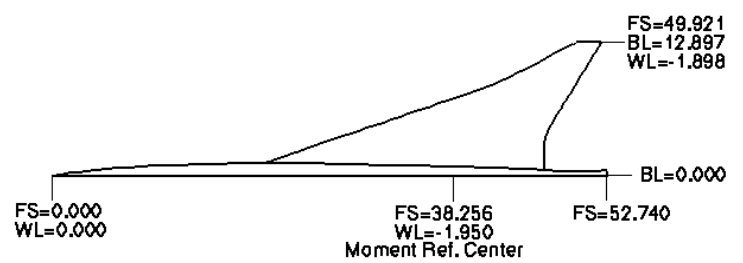

Figure 5. Planform view of the M2.4-7A model (linear dimensions in inches).

Available model components include a wing, a body truncated slightly aft of the wing trailing edge, and four diverter mounted flow through nacelles; only the wing-body configuration was tested in this investigation. Neither the wing nor the body was instrumented for surface pressure measurements; the result was a stiffer, stronger wing less susceptible to static aeroelastic deformation under load as compared to an instrumented wing. The model, shown in Figure 6, was mounted on a six-component strain gage balance, which in turn was supported by a straight sting; cavity pressures were measured and corrections applied.

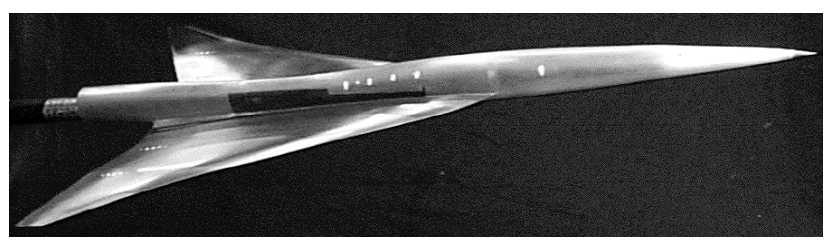

Figure 6. M2.4-7A model mounted in the PSWT. 


\section{Test Conditions and Data Quality}

Nominal test conditions were Mach 2.48, Reynolds number from 5 to 15 million per foot (corresponding to dynamic pressures from 1000 to $3000 \mathrm{psf}$ at a total temperature of $\sim 100 \mathrm{deg}$ F), and an angle-of-attack range from 3 to 3 deg. The highest Reynolds number attained was 14.21 million per foot.

The primary objective of the experimental investigation was an assessment of trip drag methods. The only configuration variable was the transition trip. Trip dots were used rather than grit, as dots were the most prevalent in HSR testing. On the wing, 5 trip heights $(\mathrm{k})$ ranging from 0.0079 to 0.0149 inches plus the trip off (free transition) condition were used. The trip location was 0.6 in. streamwise from the leading edge. On the forebody, a ring of dots 1.0 in. from the tip of the nose was used in addition to a trip off case. The trip-free configuration and a configuration with the nose trip on and a 0.0109 in. wing trip were the most heavily tested.

Data quality for this investigation was assessed in two ways: 1) a theoretical uncertainty analysis focusing on systematic or bias errors, and 2) a repeatability assessment based on data acquired throughout the test. Bias errors are important when comparing absolute levels between the experiment and computation; drag-coefficient bias uncertainty was on the order of 1.5 to 3 counts, with the higher uncertainty at higher angles-of-attack. Good repeatability was especially important for this trip drag study where highly reliable incremental results were critical. The observed variability of the drag coefficient was \pm 0.8 counts over short periods of time, and \pm 1.6 counts over the complete test. Both bias uncertainties and observed variability of lift and pitching-moment data was small.

An advantage of using the PSWT is the ability to apply both variable trip height and variable Reynolds number methods to assess trip drag, and the ability to anchor data at a relatively high Reynolds number (14.21 million per foot) that enabled nearly fully turbulent flow. The majority of the test data was acquired near 5.26 million Reynolds number per foot, which was the primary condition for which trip drag was assessed. The correction of the fixedtransition experimental data to fully turbulent conditions accounts for +1 drag count for a laminar leading-edge run, and -2.9 and -5.0 counts of trip drag at minimum drag and cruise conditions, respectively, for the baseline trip height ( $\mathrm{k}=0.0109$ in.). Computations are compared to free transition, fixed transition, and corrected-to-fully-turbulent flow data.

\section{Computational Method}

\section{A. Flow Solver}


The computational method used in the turbulence model study was version 4 of the Navier-Stokes code known as CFL3D, which is described in detail in reference 3. The code solves the 3-D time-dependent thin-layer NavierStokes equations with a finite-volume formulation. The governing equations are discretized to be consistent with conservation laws in integral form, and are solved using a second-order accurate upwind-biased spatial differencing scheme. Roe's flux-difference splitting ${ }^{19}$ is used to construct the upwind differences for the convective and the pressure terms. The spatial derivatives are written conservatively as a flux balance across the cell, and the shear stress and heat transfer terms are centrally differenced. Spatial approximate factorization and Euler backward integration after linearization in time results in the solution through $5 \times 5$ block-tridiagonal matrix inversions in three directions. An approximate diagonal form of the spatial factors is employed to reduce computational time. Convergence acceleration is obtained by using a multigrid full-approximation scheme and mesh sequencing for flow initialization.

\section{B. Turbulence Model}

The Reynolds stresses are modeled using one of five turbulence models implemented in the flow solver: Baldwin-Lomax with the Degani Schiff modifications, Baldwin-Barth, Spalart-Allmaras, Menter's SST, and GatskiSpeziale k- $\omega$ model.

\section{Baldwin-Lomax with Degani-Schiff modification}

The Baldwin-Lomax two layer algebraic turbulence model is described in detail in reference 4. This model was used widely throughout the CFD community until the mid-1990's; its capabilities and limitations are well known. In short, it is generally considered a good model for the prediction of attached flows, but is deficient for flows with any significant separated regions. In particular, the Baldwin-Lomax model tends to predict shocks too far downstream for separated transonic flows over aerodynamic configurations. Degani and Schiff 5 modified the original BaldwinLomax model to extend the model in a rational manner to permit an accurate determination of the viscous length scale for high-angle-of-attack flows in regions of crossflow separation, where a strong leeward vortical flow structure exists. Throughout this paper, the Baldwin-Lomax model with the Degani-Schiff modifications is abbreviated as B-L. It is acknowledged that the Spalart-Allmaras model has become the turbulence model of choice for many CFD users today, and that it likely would have been chosen had this investigation been initiated today. Nevertheless, the B-L model provided sufficient, consistent results during the current investigation. 


\section{Baldwin-Barth}

The Baldwin-Barth (B-B) turbulence model is described in detail in reference 6. This model is a one-equation turbulence model derived from a simplified form of the $\mathrm{k}-\varepsilon$ equations. The model solves a partial differential equation (PDE) over the whole field for the turbulent Reynolds number, which is directly related to the kinematic eddy viscosity $v_{t}$. In this formulation of the B-B turbulence model, the thin-layer assumption has been used for the source term. The PDE is solved implicitly using 3-factor approximate factorization, with first-order upwind differencing used on the advective terms. Local time stepping is employed to accelerate convergence.

\section{Spalart-Allmaras}

The Spalart-Allmaras (S-A) turbulence model is a one-equation turbulence model derived "using empiricism and arguments of dimensional analysis, Galilean invariance, and selective dependence on the molecular viscosity." Further details can be found in reference 7. The S-A model is very similar in form to the B-B model, although the SA model includes a destruction term that is not present in the other model. This lack of a destruction term in the B-B model is responsible for a mild inconsistency in modeling isotropic turbulence and could also invalidate the model in the class of shear flows in which $v_{\mathrm{t}}$ decreases such as an axisymmetric wake. The PDE is solved using the same implicit method used in the B-B model.

\section{Menter's SST.}

The Menter Shear-Stress Transport (SST) turbulence model is a modified version of the k- $\omega$ two-equation turbulence model. This model is based on Bradshaw's assumption that the principal shear stress is proportional to the turbulent kinetic energy, which is introduced into the definition of the eddy-viscosity. This model transforms a k- $\varepsilon$ model into a $\mathrm{k}-\omega$ formulation. This model is described in greater detail in reference 8 .

\section{Gatski/Speziale k- $\omega$ model.}

The EASM (Explicit Algebraic Stress Model) is derived directly from the modeled transport equation for the Reynolds stress tensor, with isotropic dissipation rate and an assumed linear form for the pressure-strain correlation tensor. An algebraic relation results by assuming an equilibrium hypothesis and a functional form for diffusive effects. Next, an explicit relation can be derived in terms of an n-term basis. The model can be cast in two-equation form (such as k- $\varepsilon$ or k- $\omega$ ), and solved at little additional expense. It yields an explicit representation for the Favreaveraged correlation tensor, and is fully nonlinear. In CFL3D, a three-term integrity basis is employed. Constants from the Speziale-Sarkar-Gatski pressure-strain correlation model are used. In the originally developed EASM 
approach, the value of $\mathrm{P} / \varepsilon$ (where $\mathrm{P}$ is production and $\varepsilon$ is turbulent dissipation rate) is assumed to be a constant. With this assumption, $\mathrm{C} \mu$ (which appears in the relation that determines the eddy viscosity) is determined through an explicit relation, which is typically regularized to avoid possible numerical problems. In the more recent (and now recommended) EASM methodology, the value of $\mathrm{P} / \varepsilon$ is allowed to vary. When this is done, $\mathrm{C} \mu$ must be determined through the solution of a cubic equation. A full description is available in reference 9. The preliminary implementation of this model was used for this study.

\section{Grid Generation}

\section{Reference H Configuration}

Three grids were generated for the NTF 2.2\% HSR Reference H baseline in order to assess the effect of grid topology and the representation of the actual wind tunnel model geometry. The different topologies and geometric representations were chosen because these topologies and geometric representations are the most common ones used for this configuration.

The first grid was a two-block grid with an $\mathrm{O}-\mathrm{C}(\mathrm{O}$ in the streamwise direction and $\mathrm{C}$ in the spanwise direction) topology with a 5-inch full-scale transition from blunt to sharp leading edge at the crank location on the wing. This grid had 105 points in the streamwise direction, 177 points in the spanwise direction and 81 points normal to the surface in the first block, which defines the wing/body configuration; the second block, which defines the sting, had 49 points in the streamwise direction, 177 points in the spanwise direction, and 81 points normal to the surface. The total number of grid points was $2,207,898$. The normal spacing adjacent to the surface was $5 \times 10^{-5}$ over the entire surface. The surface spacing distribution corresponds to a non-dimensional $\mathrm{y}^{+}$value of approximately 1.6 for $M=0.90$ and $\operatorname{Re}_{\mathrm{c}}=30 \times 10^{6}$. The farfield boundary extends to 20 chord lengths in the circumferential and upstream directions and the second block extends approximately 20 chords downstream of the first block.

The second grid used was a single block $\mathrm{C}-\mathrm{O}(\mathrm{C}$ in the streamwise direction and $\mathrm{O}$ in the spanwise direction) topology grid with a 5-inch full-scale transition from blunt to sharp wing leading edge at the crank; this grid defines both the wing/body configuration and the sting. This grid had 133 points in the spanwise direction, 249 points in the streamwise direction and 81 points in the normal direction. The total number of grid points was $2,682,477$. The normal spacing was $5 \times 10^{-5}$ over the entire surface. The surface spacing distribution corresponds to a nondimensional $\mathrm{y}^{+}$value of approximately 1.0 for $\mathrm{M}=0.90$ and $\mathrm{Re}_{\mathrm{c}}=30 \times 10^{6}$. The farfield boundary extends to 20 chords in the circumferential, upstream, and downstream (of the wing/body configuration) directions. Figure 7 shows the 
differences in the surface grids of the O-C grid on the wing with a 5-inch full-scale transition from blunt to sharp wing leading edge and the $\mathrm{C}-\mathrm{O}$ grid on the wing with a 5-inch full-scale transition from blunt to sharp wing leading edge. Figure 8 and Figure 9 show that the $\mathrm{C}-\mathrm{O}$ grid is converged for drag at the given conditions and that both grids are converged for lift. The poor convergence quality of the $\mathrm{O}-\mathrm{C}$ grid is believed to be due to a lack in the grid quality. The results presented in this paper are for the finest mesh and the differences due to the mesh topology will be discussed subsequently.

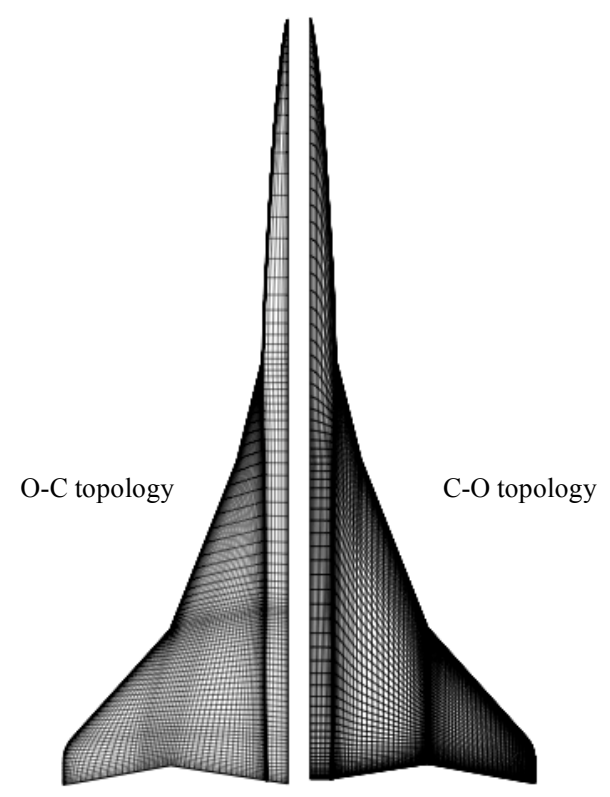

Figure 7. Wireframe surface grids of $\mathrm{O}-\mathrm{C}$ and $\mathrm{C}-\mathrm{O}$ topologies.

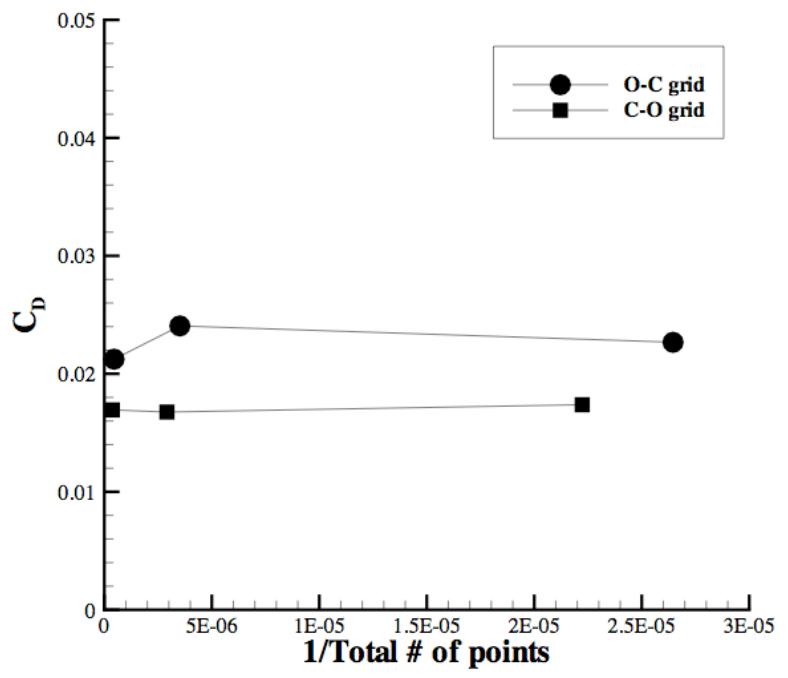

Figure 8. Grid density study, $M=0.90, \alpha=5.0 \mathrm{deg}, \operatorname{Re}_{\mathrm{c}}=30 \times 10^{6}$. 


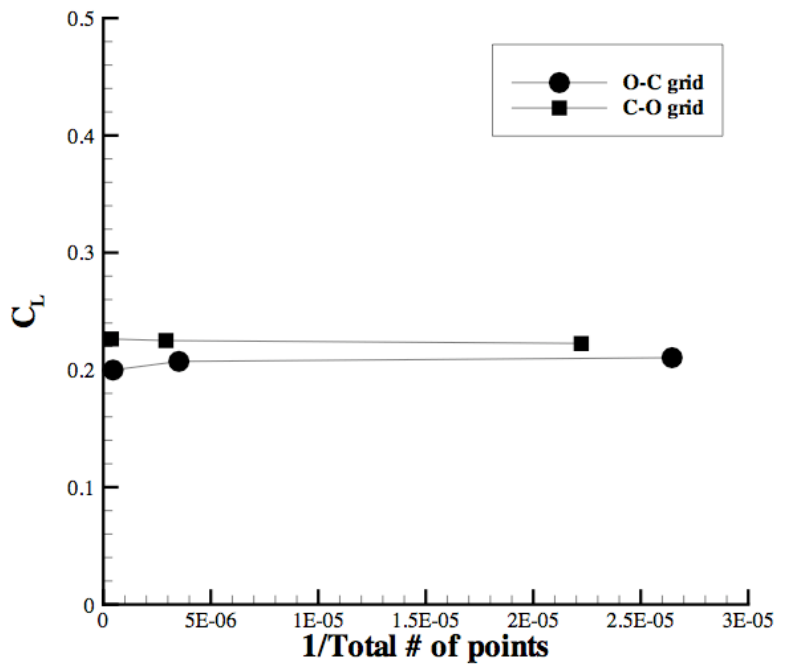

Figure 9. Grid density study, $M=0.90, \alpha=5.0 \mathrm{deg}, \operatorname{Re}_{\mathrm{c}}=30 \times 10^{6}$.

The wind tunnel model had a discontinuity between the sharp wing leading edge and the blunt wing leading edge at the crank. In an attempt to model this discontinuity, a third grid was generated which was identical to the second grid (C-O topology) with the exception of a 1-inch, rather than 5-inch, full scale geometric transition region between the blunt and sharp wing leading edges at the crank. Figure 10 shows the differences in the surface grids of the C-O grid on the wing with a 5-inch full-scale transition from blunt to sharp wing leading edge and the C-O grid on the wing with a 1-inch full-scale transition from blunt to sharp wing leading edge. The sketch shows where the geometric wedge is on the wing and what is meant by 1 -inch versus 5-inch full-scale geometric transition from blunt to sharp wing leading edge. Figure 11 shows a representation of the volume grid for the C-O grid topology with a 1inch full-scale transition from blunt to sharp wing leading edge.

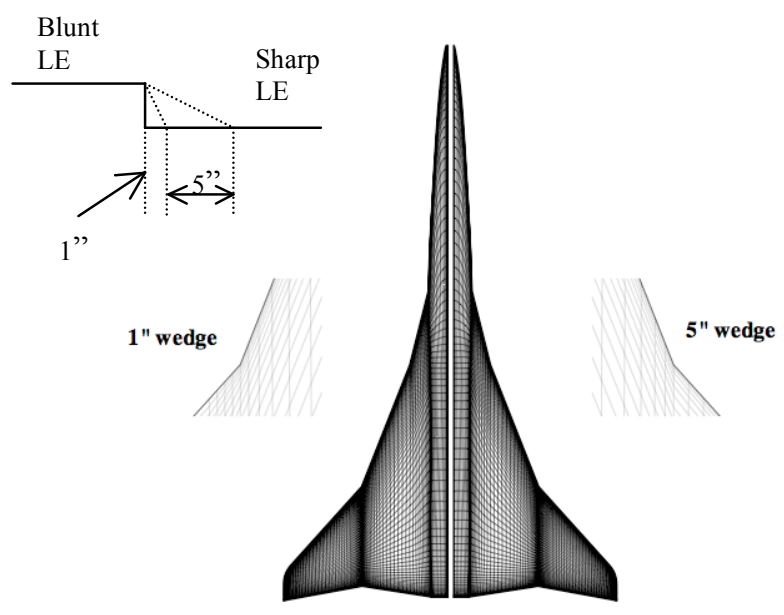

Figure 10. Wireframe surface grids of C-O topology 1 " wedge and 5" wedge. 


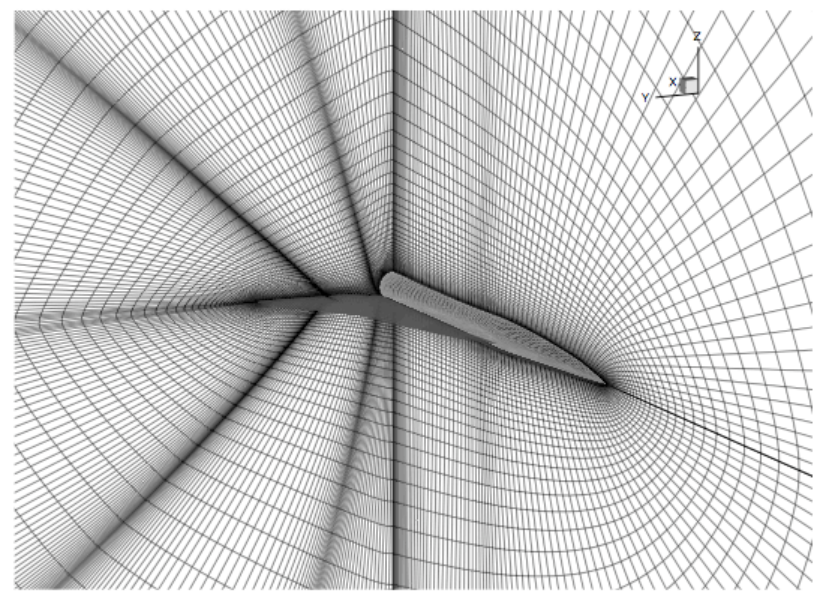

Figure 11. Representation of the C-O type volume grid for the Reference $H$ configuration.

\section{M2.4-7A Configuration}

A single block C-O topology grid was used to model the M2.4-7A geometry. This grid had 93 points in the spanwise direction, 241 points in the streamwise direction and 65 points in the normal direction to give a total number of grid points of $1,456,845$. The grid distribution normal to the surface corresponds to a non-dimensional $\mathrm{y}^{+}$ value of approximately 1.0 for the baseline conditions.

\section{Convergence}

The solutions were considered converged when the drag coefficient changed less than one count over 100 iterations and the residual was decreased by at least three orders of magnitude. Figure 12 and Figure 13 show a typical residual history and drag convergence for the Reference $H$ configuration at $\alpha=5$ deg. These histories are typical of all of the turbulence models and angles-of-attack. All computations were made on the Langley Cray YMP and the NAS Cray C-90.

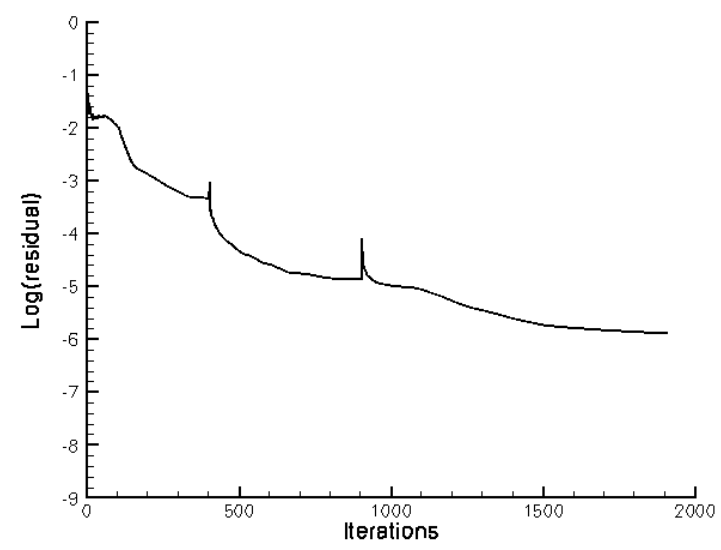

Figure 12. Typical Residual History for the Reference H 2.2\% NTF Model. 


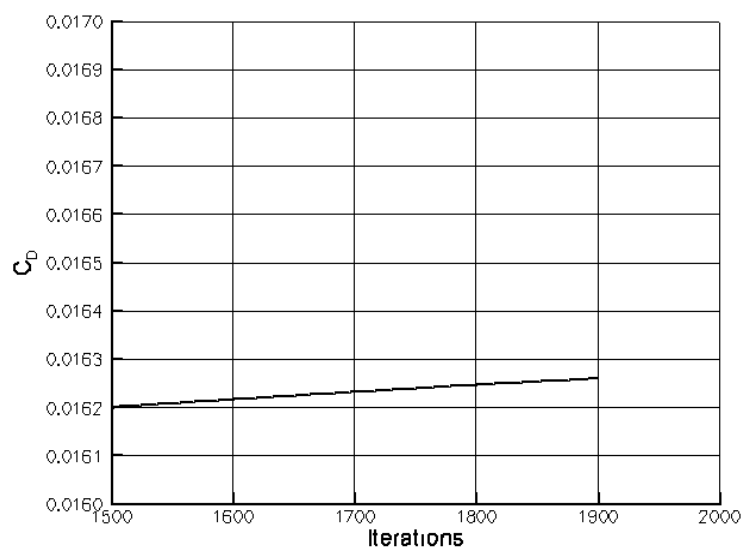

Figure 13. Typical Drag Convergence for the Reference H 2.2\% NTF Model.

The supersonic solutions were also considered converged when the drag coefficient changed less than one drag count over 100 iterations and the residual was decreased by at least three orders of magnitude. Typical residual histories and drag convergence plots for the M2.4-7A configuration are shown in Figure 14 and Figure 15, respectively.

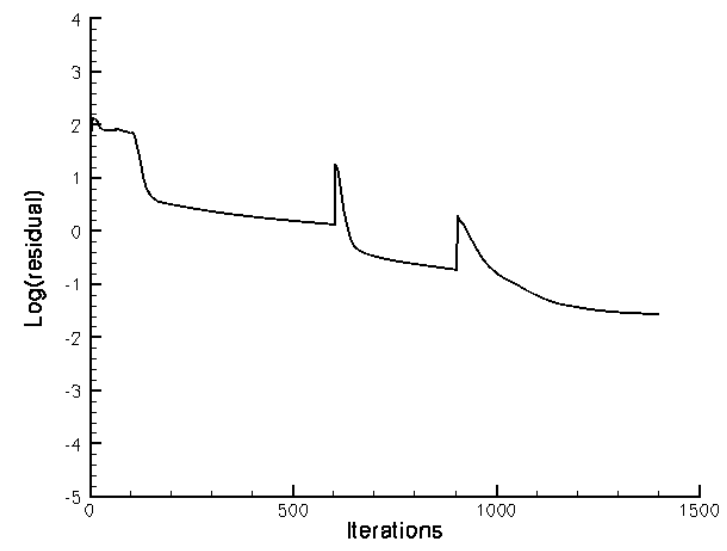

Figure 14. Typical Residual history for the M2.4-7A model. 


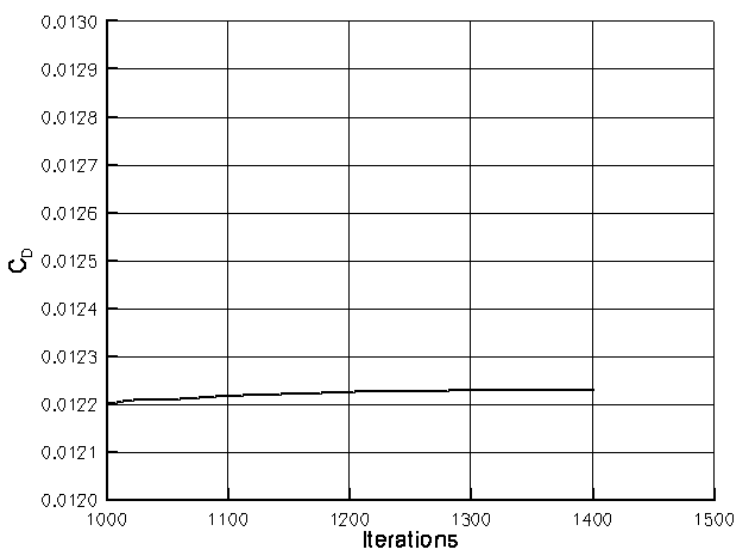

Figure 15. Typical Drag Convergence for the M2.4-7A model.

\section{Results and Discussion}

\section{A. Grid Topology and Wedge Size}

A grid study was performed using these three grids in an effort to determine which grid gave the best comparisons with the experimental data. All of the runs made for this grid study were performed at a $\mathrm{M}=0.90$, $\operatorname{Re}_{\mathrm{c}}=30 \times 10^{6}$, and at an angle-of-attack of 5 degrees. These runs were all made with CFL3D using the S-A turbulence model. Figure 16 shows the pressure distributions at the six spanwise stations on the wing of the HSR 2.2\% NTF geometry for the $\mathrm{C}-\mathrm{O}$ topology, $\mathrm{O}-\mathrm{C}$ topology, and the experimental data and Figure 17 shows the pressure contours for the two topologies. As shown in Figure 16, the two topologies both show similar agreement with the experimental data, except aft of the crank of the wing $(x=46.5$ in.) where the $C-O$ topology picks up more of the characteristics of the experimental pressure distribution than the O-C topology. The pressure contours in Figure 17 show that the $\mathrm{C}-\mathrm{O}$ grid topology yields a different surface pressure distribution than the $\mathrm{O}-\mathrm{C}$ grid topology primarily on the outboard wing panel. 


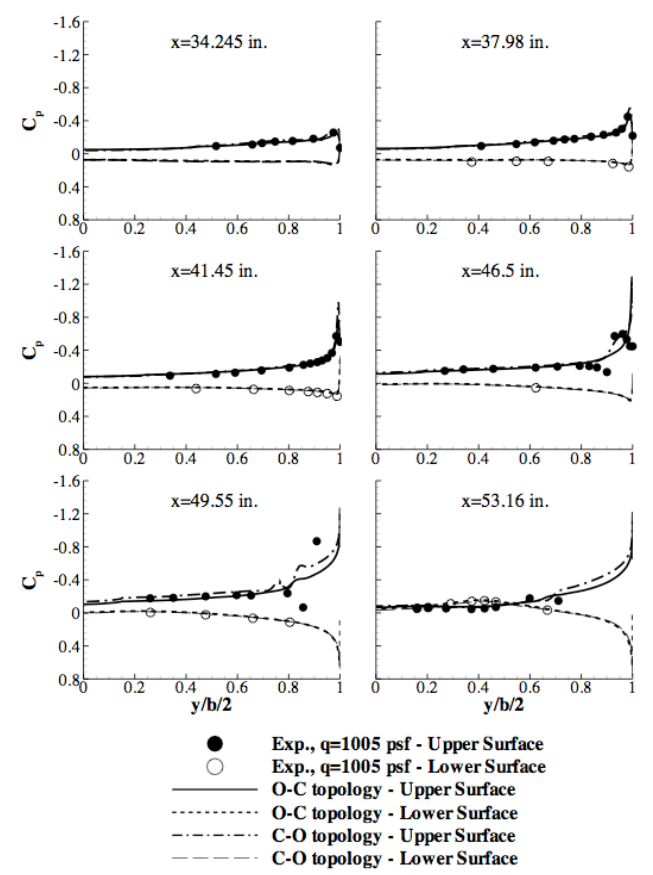

Figure 16. Surface Pressure Comparison, $M=0.90, \alpha=5.0 \mathrm{deg}, \operatorname{Re}_{\mathrm{c}}=30 \times 10^{6}, \mathrm{~S}-\mathrm{A}$ turbulence $\operatorname{model}$.

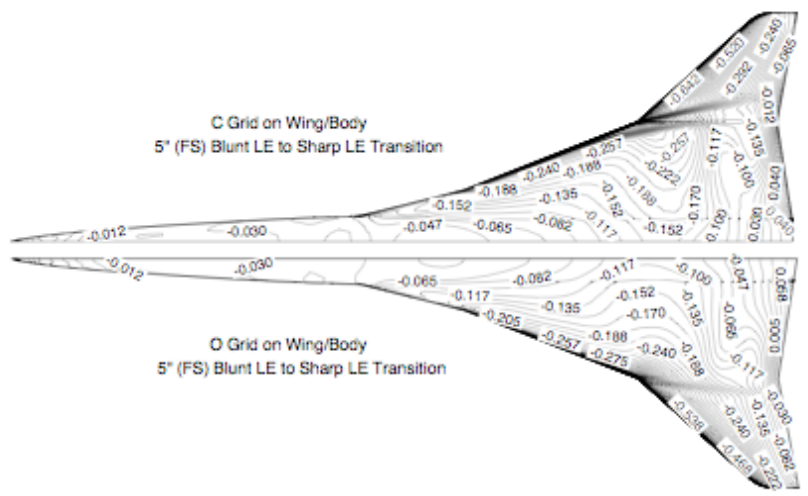

Figure 17. Pressure Contour Comparison, $M=0.90, \alpha=5.0 \mathrm{deg}, \operatorname{Re}_{\mathrm{c}}=30 \times 10^{6}, \mathrm{~S}-\mathrm{A}$ turbulence $\operatorname{model}$.

Figure 18 shows the pressure distributions at the six spanwise stations on the wing of the HSR $2.2 \%$ NTF geometry for the 1 -inch full-scale wedge versus the 5-inch full-scale wedge and Figure 19 shows the pressure contours of the two wedge sizes. As shown in these two figures, the wedge size does not have a significant effect on the pressure distributions or the pressure contours. After looking at the results from these two studies, it was decided to use the single block $\mathrm{C}-\mathrm{O}$ grid with 1 -inch wedge for the turbulence model study since the 1 inch wedge more closely represents the actual wind tunnel model geometry. 


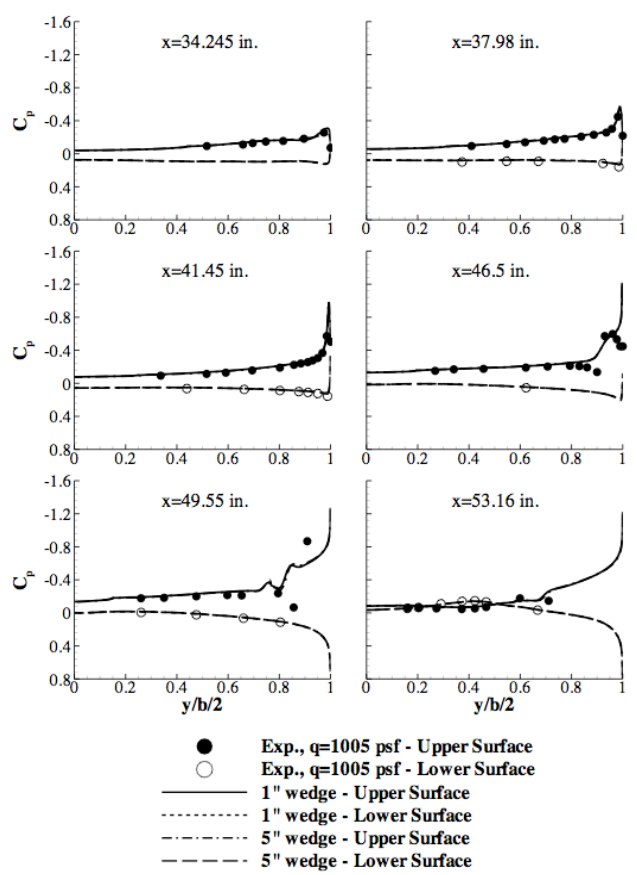

Figure 18. Surface Pressure Comparison, $M=0.90, \alpha=5.0 \mathrm{deg}, \operatorname{Re}_{\mathrm{c}}=30 \times 10^{6}, \mathrm{~S}-\mathrm{A}$ turbulence $\operatorname{model}$. 5 " wedge

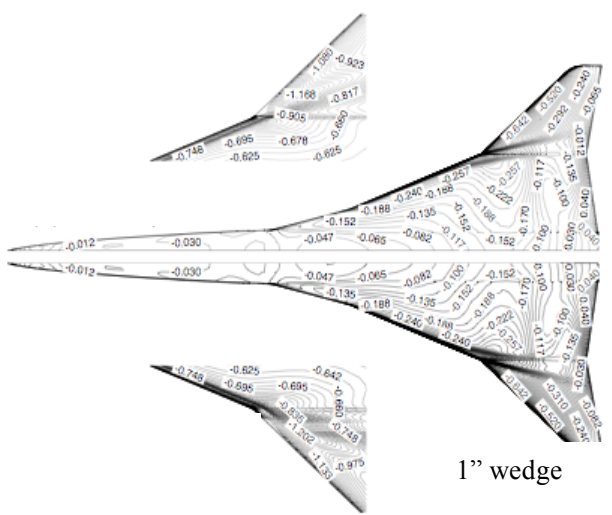

Figure 19. Pressure Contours, $M=0.90, a=5.0 \mathrm{deg}, \operatorname{Rec}=30 x 106, \mathrm{~S}-\mathrm{A}$ turbulence model.

\section{B. Code Modifications}

During the course of this study, the CFL3D Navier-Stokes code was modified to increase the calculation accuracy of the minimum distance function by incorporating a surface interpolation scheme based on normal projection. The prior approach used the nearest body cell-center point. This modification only affected the results of the S-A and SST turbulence models. Figure 20 and Figure 21 show that the modification made to the code does not significantly effect the pressure distributions when using either the S-A turbulence model or the Menter's SST turbulence model, respectively. Figure 22, however, indicates that the forces are affected by this modification to CFL3D. This change is seen because the modification changes the solution, which in turn results in a change in the 
integrated forces. For the S-A case, the lift is increased by approximately 0.004 and the drag is decreased by approximately 20 drag counts. For the Menter's SST results, the lift remains about the same but the drag is increased by 3 drag counts. The change to the code brought the two calculations in closer agreement with each other and closer to the experimental data. This modification also decreased the amount of computer time needed to obtain a converged solution by approximately $40 \%$ for the S-A case. The SST case was restarted from the previous runs using the new code while the S-A case was completely re-run using the new code; therefore the amount of time savings for the SST case is unknown but it is expected to decrease the amount of computational time by about the same amount as observed with the S-A model.
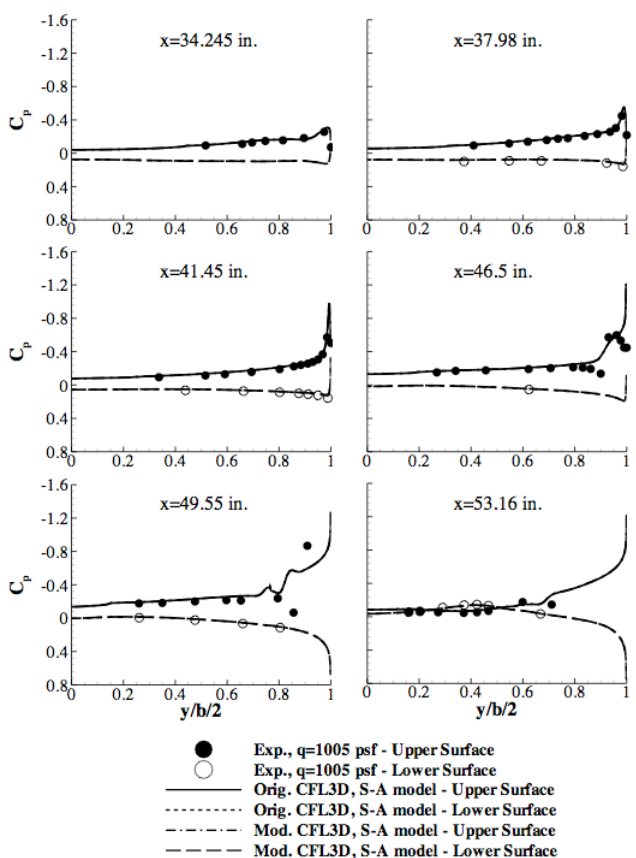

Figure 20. Code comparison, $M=0.90, \alpha=5.0 \mathrm{deg}, \mathrm{Re}_{\mathrm{c}}=\mathbf{3 0 \times 1 0 ^ { 6 }}, \mathrm{S}-\mathrm{A}$ turbulence model. 


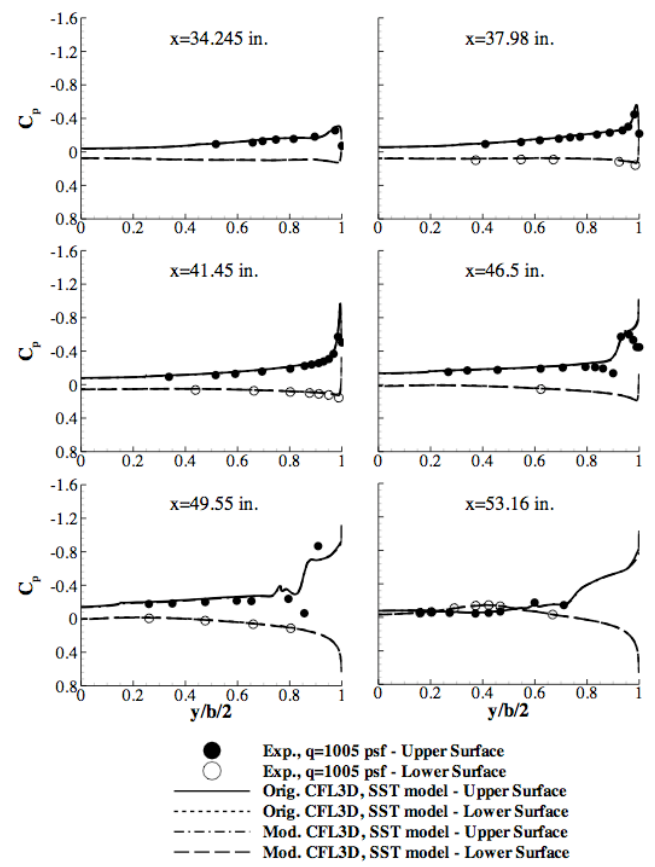

Figure 21. Code comparison, $M=0.90, \alpha=5.0 \mathrm{deg}, \mathrm{Re}_{\mathrm{c}}=30 \times 10^{6}$, Menter's $\mathrm{SST}$ turbulence model.

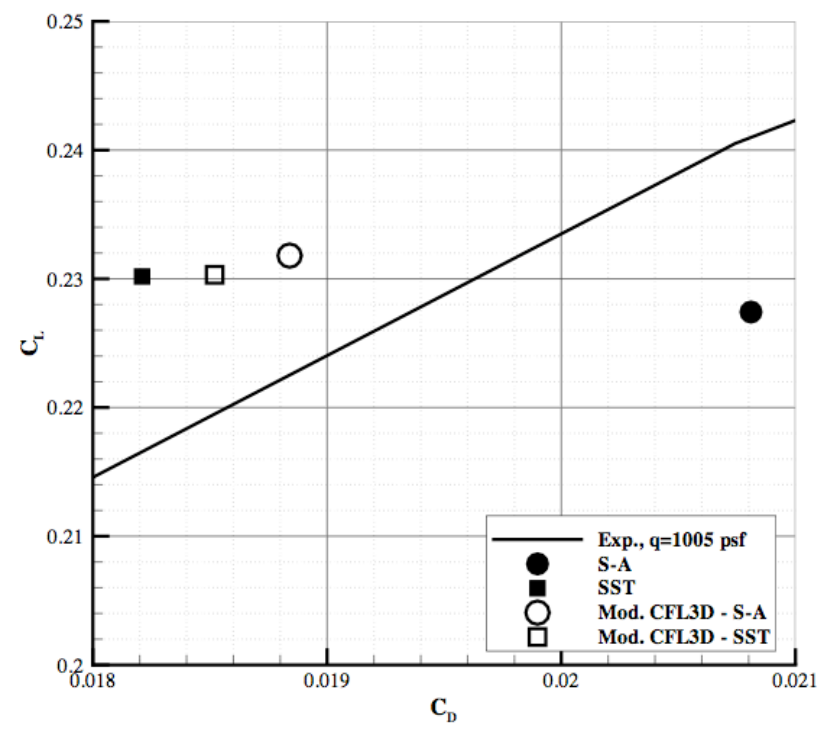

Figure 22. Drag Polar for the Code-to-Code Comparisons, $M=0.90, \alpha=5.0 \mathrm{deg}, \operatorname{Re}_{\mathrm{c}}=30 \times 10^{6}$.

\section{Comparisons at Transonic Conditions}

1. Pressure Comparisons

The spanwise and chordwise pressure distributions for the $\alpha=1.0$ deg case are shown in Figure 23 and Figure 24 , respectively. These figures indicate that for this low angle-of-attack, all of the turbulence models agreed well with the experimental data at all six spanwise and three chordwise pressure stations. This behavior is expected since this relatively benign flow is mostly attached and all the models should behave the same for attached flow. The spanwise 
and chordwise pressure distributions for the $\alpha=5.0$ case are shown in Figure 25 and Figure 26, respectively. The spanwise pressure distributions for the $\alpha=5.0$ case indicate that up to the crank in the wing, all of the turbulence models predict the flow characteristics very well. At the crank region $(x=46.5$ inches $)$ none of the models pick up the detail seen in the outboard $20 \%$ span in the experimental data. At an x station of 49.55 inches, B-L is the only model that picks up the apparent suction peak at $90 \%$ span in the experimental data. At the $x=53.16$ inches station, all of the models perform equally well, with B-L showing a suction peak at approximately $80 \%$ span. The experimental pressures do not extend this far outboard; therefore it is difficult to say if the suction peak is real. The chordwise pressure distributions show that for the $\alpha=5.0 \mathrm{deg}$ case, all four of the models give good agreement with experimental data at the first two y locations. At the $y=9.95$ inches location, none of the models match the pressure measurement on the upper surface.

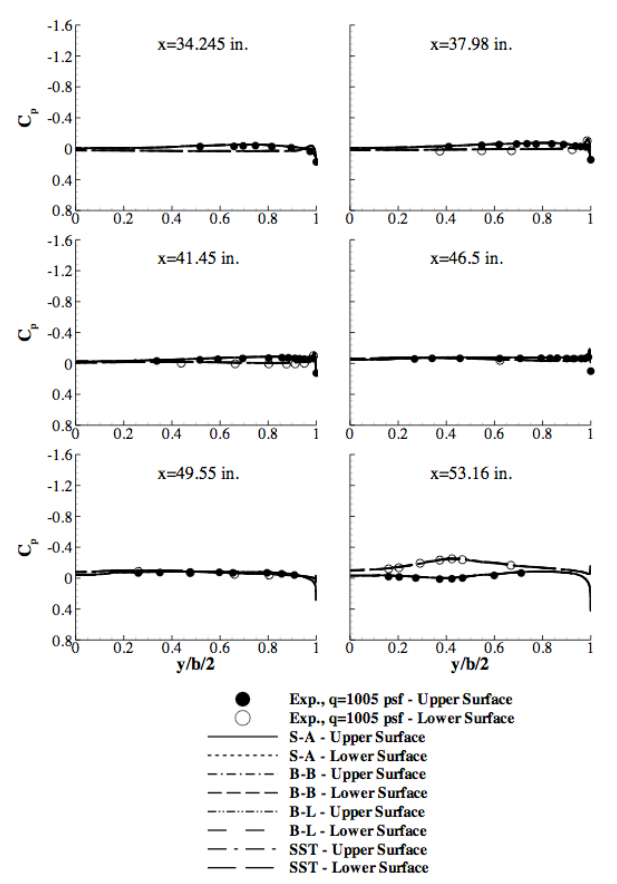

Figure 23. Spanwise Pressure Distribution, $\alpha=1.0$ deg. 

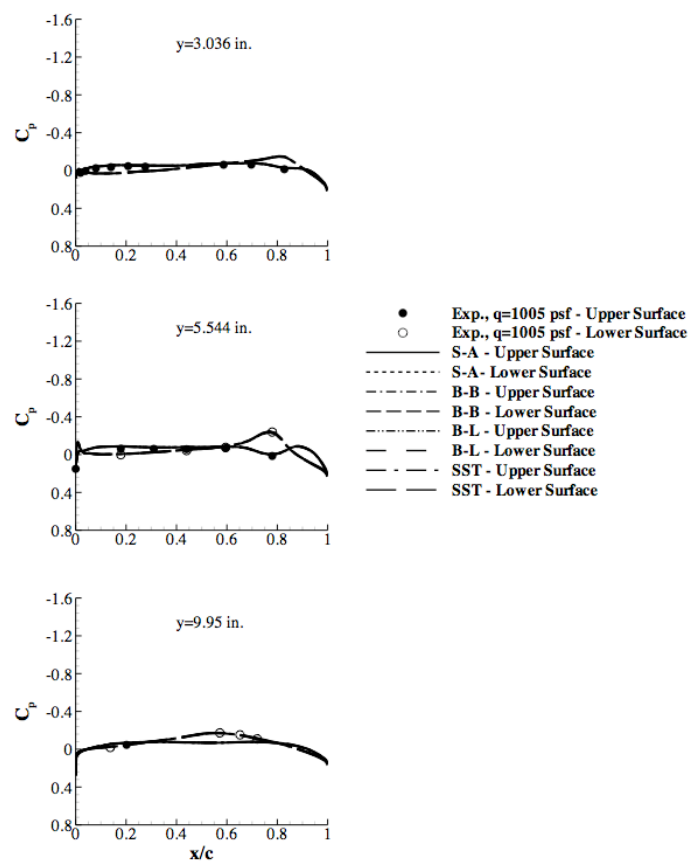

Figure 24. Chordwise Pressure Distribution, $\alpha=1.0$ deg.

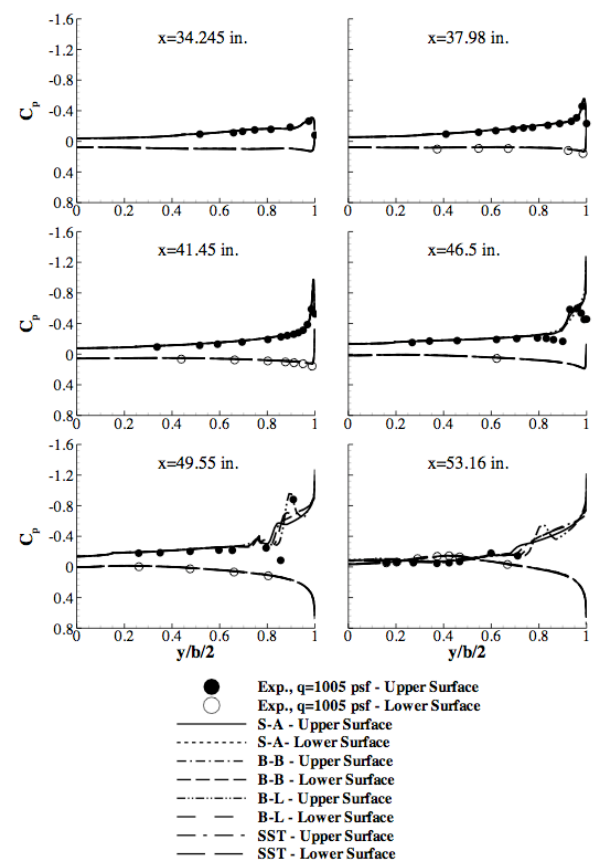

Figure 25. Spanwise Pressure Distribution, $\alpha=5.0 \mathrm{deg}$. 

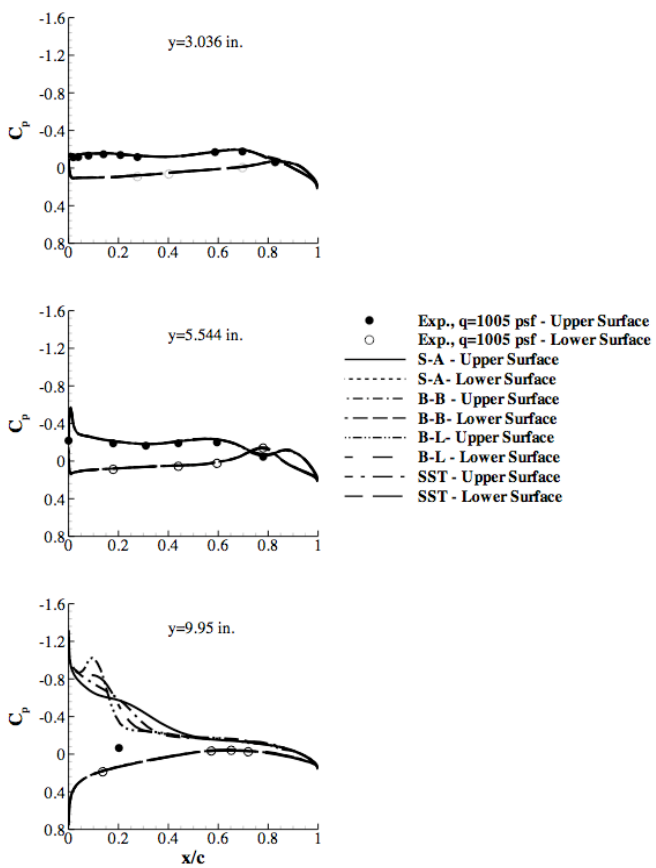

Figure 26. Chordwise Pressure Distribution, $\alpha=5.0$ deg.

The spanwise and chordwise pressure distributions for the $\alpha=10.0$ deg case are shown in Figure 27 and Figure 28 , respectively. The spanwise pressure distributions for the $\alpha=10.0$ deg case indicate that at the $\mathrm{x}$ station of 34.245 , all of the models predict the flow similarly, and this prediction varies slightly from the experimental flow. At the next two stations, i.e. $x=37.98$ in. and $x=41.45$ in., none of the models pick up the magnitude of the suction peak seen at approximately $90 \%$ span and $85 \%$ span, respectively, in the experimental flow. At the crank region, i.e. $\mathrm{x}=46.5$ inches, the B-L model overpredicts the suction peak seen at approximately $80 \%$ span in the experimental data by approximately the same amount that the other three models underpredict the height of the suction peak. At an $\mathrm{x}$ station of 49.55 inches, B-L comes the closest to matching the fluctuations in the experimental data. At the $\mathrm{x}=53.16$ inches station, B-L comes the closest of the four models to picking up the upper surface pressure distribution seen in the experiment. The chordwise pressure distributions show that for the $\alpha=10.0$ deg case, none of the models pick up the dip in the pressure curve which occurs at $60 \%$ chord in the experimental data at the $y=3.036$ in. station. At the second y location, $y=5.544$ inches, B-L comes the closest to picking up the drop in the pressure curve at $30 \%$ chord but all four models pick up the pressure at $60 \%$ chord. At the $y=9.95$ inches location, all of the models come close to predicting the experimental value for the upper surface pressure; B-L shows some fluctuations in the pressure distribution which the other models do not predict. There is no way of knowing if these fluctuations do really occur in nature since there were no pressure values taken experimentally. 


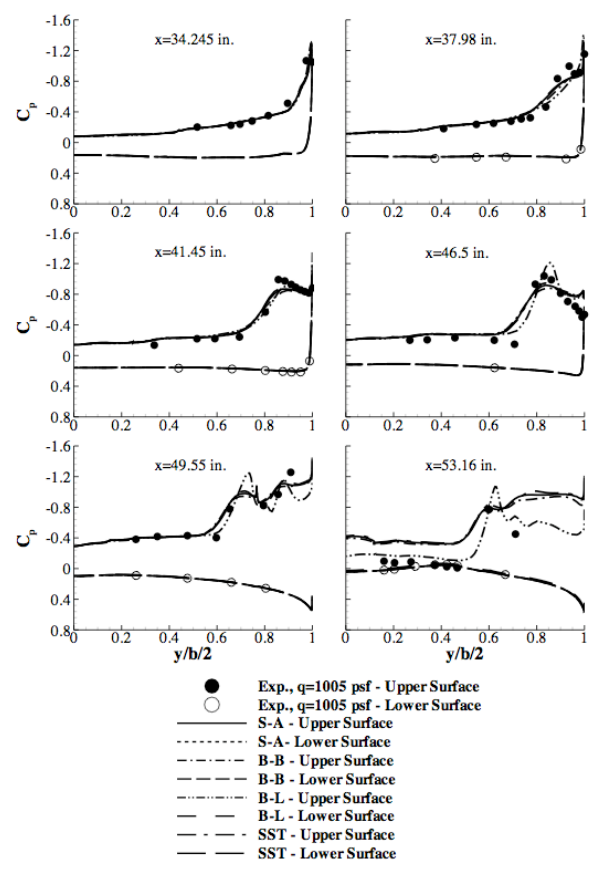

Figure 27. Spanwise Pressure Distribution, $\alpha=10.0$ deg.
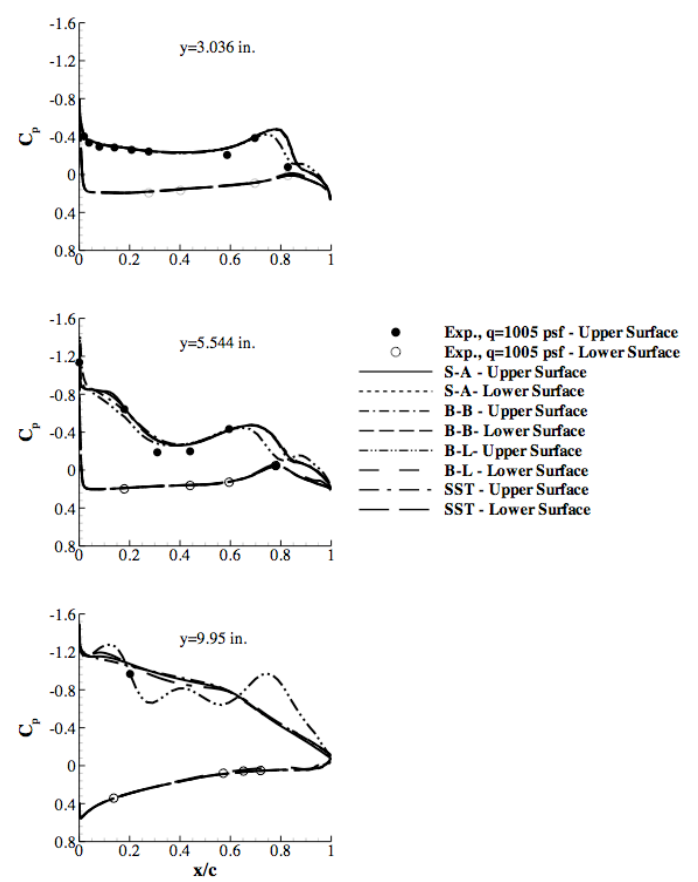

Figure 28. Chordwise Pressure Distribution, $\alpha=10.0$ deg.

\section{Force and moment comparisons.}

Figure 29 shows the drag polar for the four turbulence models and the experimental data. At $\alpha=1.0$ deg, S-A is the only turbulence model that overpredicts the drag level. At the design point, $\alpha=5.0 \mathrm{deg}$, B-B is approximately 1 
drag count low, with S-A, SST, and B-L being 4, 6, and 13 drag counts low, respectively. At $\alpha=10.0$ deg, all of the models predict the drag levels low.

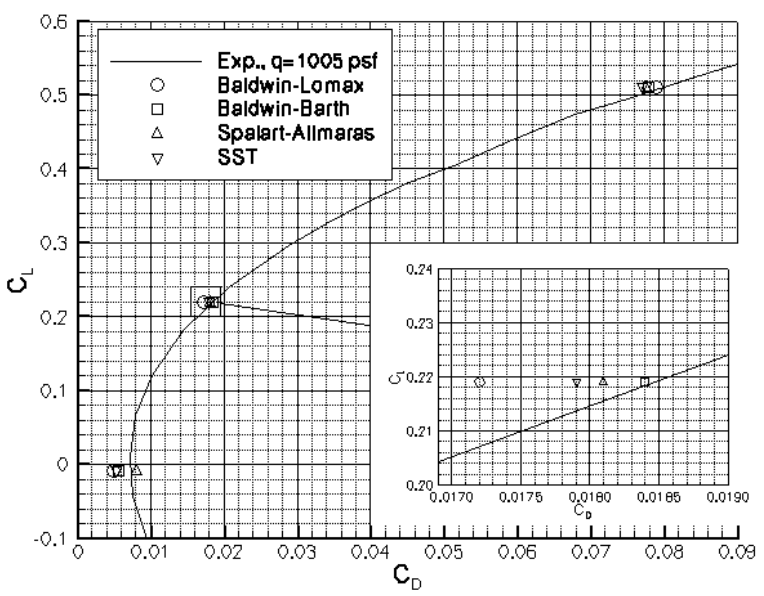

Figure 29. Drag Polar for the NTF Ref. $H$ at $M=0.90, R_{c}=30 \times 10^{6}$.

Figure 30 shows the lift curve for the four turbulence models and the experimental data. At $\alpha=1.0$ deg, all of the models are slightly higher than the experimental data. At the design point, $\alpha=5.0$ deg, B-L is closer to the experimental lift curve than the other three models; at $\alpha=10.0 \mathrm{deg}$, B-L is also closer to the experimental lift curve than the other three models. It should be noted that the computations were for the rigid, 1 -g geometry while the wind tunnel model is flexible and does experience a wing-tip wash-out under load ${ }^{15}$. The effect of the washout under load is a reduced lift at constant angle-of-attack relative to the rigid shape; this effect is not accounted for in the comparisons shown.

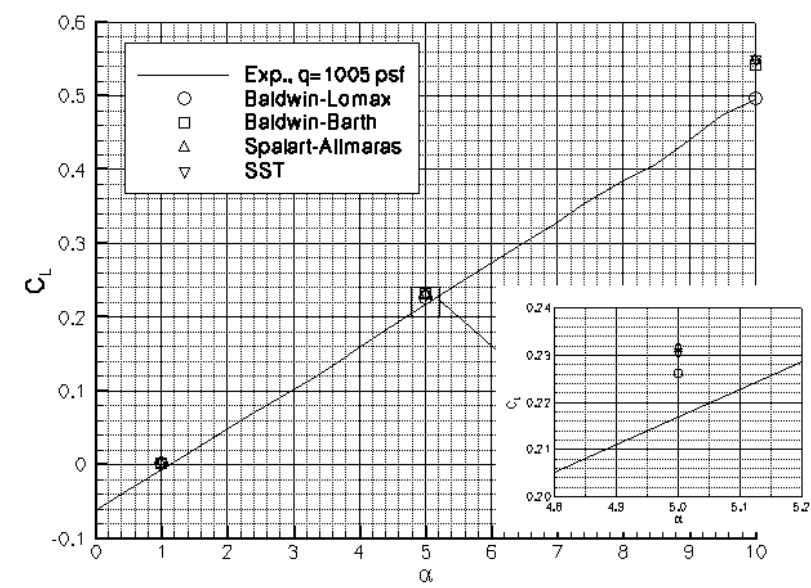

Figure 30. Lift Curve for the NTF Ref. $H$ at $M=0.90, \operatorname{Re}_{c}=30 \times 10^{6}$.

The lift-to-drag ratios for the four turbulence models and the experimental data are shown in Figure 31 . This figure shows that at $\alpha=1.0 \mathrm{deg}$, all four of the models come close to matching the experimental value. At $\alpha=5.0 \mathrm{deg}$, 
B-B matches the experimental data, while the other three models predict the $\mathrm{L} / \mathrm{D}$ values high. At $\alpha=10.0 \mathrm{deg}$, all of the turbulence models come close to matching the $\mathrm{L} / \mathrm{D}$ values.

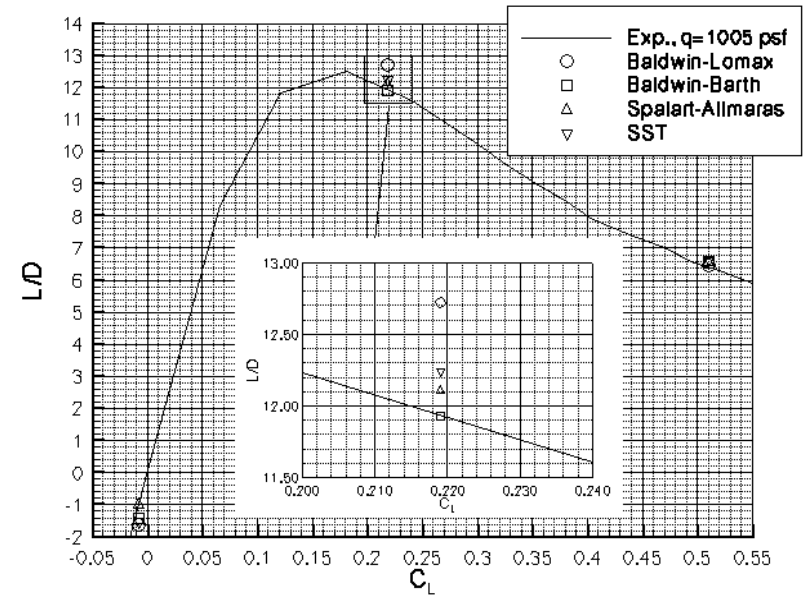

Figure 31. Lift-over-Drag Curve for the NTF Ref. $H$ at $M=0.90, \operatorname{Re}_{c}=30 \times 10^{6}$.

Figure 32 shows the pitching moment curves for the four turbulence models and the experimental data. At $\alpha=1.0$ deg, all of the models underpredict the pitching moment (predictions are more nose-down than experiment). At $\alpha=5.0 \mathrm{deg}$, all of the models again underpredict the pitching moment, but B-L comes the closest to the experimental values. At $\alpha=10.0 \mathrm{deg}$, all of the models again underpredict the pitching moment, but B-L comes the closest to the experimental values. As mentioned previously, accounting for the wing-tip washout effect of the flexible wind tunnel model relative to the rigid computations would tend to improve the comparisons.

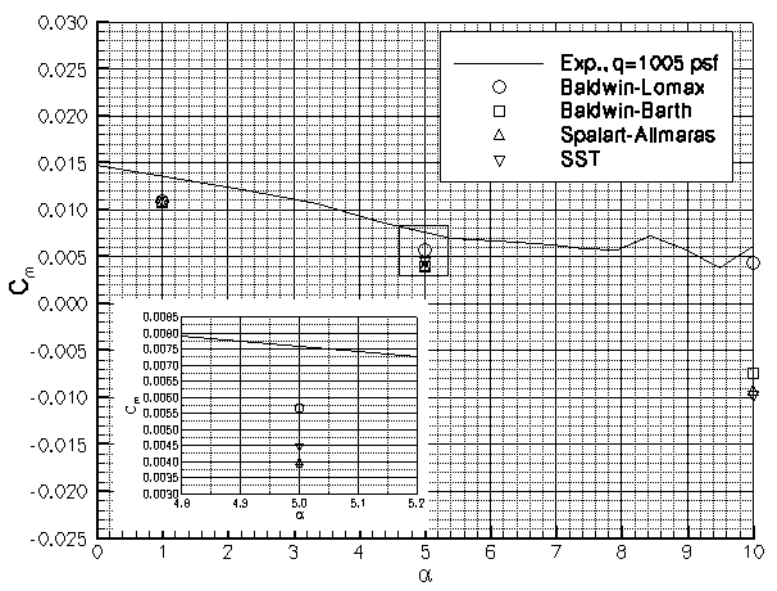

Figure 32. Pitching Moment Curve for the NTF Ref. $H$ at $M=0.90, \operatorname{Re}_{\mathrm{c}}=30 \times 10^{6}$.

The computed wing pressure distributions discussed in reference 20 indicated that B-L agreed the best with the experimental data at $\alpha=5.0$ deg while the drag data in Figure 29 indicate that the B-B model agrees somewhat better with experiment at $\alpha=5.0$ degrees. This discrepancy is believed to be caused by a difference in the viscous drag 
components of the turbulence model results. The B-L turbulence model viscous drag component results are approximately 10 drag counts lower than the other three models at all three angles-of-attack. At $\alpha=10.0$ deg, the pressure component of drag for B-L is approximately 60 drag counts lower than the other three models, which can account for the results seen at this angle-of-attack. Note also that the equivalent flat plate viscous drag is 0.0064 for $M=0.90$ and $\operatorname{Re}_{c}=30 \times 10^{6}$, which is $7-17$ counts higher than the computations herein. Figure 33 shows that if the flat plate equivalent viscous drag component is substituted for the computational viscous drag component, the computational data are more consistent between turbulence models, and agree better overall with the experimental data.

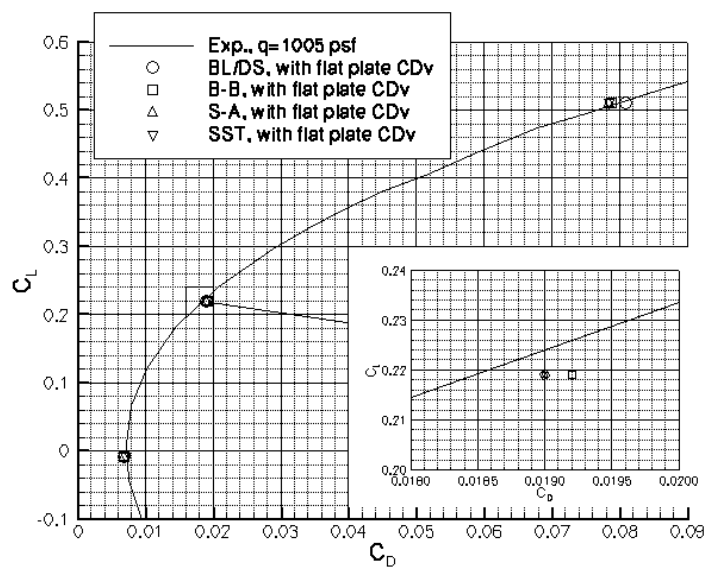

Figure 33. Drag Polar using flat plate equivalent viscous drag instead of computational viscous drag component for the NTF $R$ ef. $H$ at $M=0.90, \operatorname{Re}_{c}=30 \times 10^{6}$.

These results show that the computed forces and moments compared reasonably well with the experimental data, with the B-L and B-B models showing the best agreement. None of the turbulence models predict the experimental flow well at all of the conditions tested herein. B-L seems to give the best agreement with the force data at the higher angles-of-attack, while B-B agrees better with the force data at the lower angles-of-attack. Also, the substitution of the theoretical equivalent flat plate viscous drag for the Navier-Stokes computed viscous drag significantly improves the consistency of results between turbulence models and the overall agreement between the computational and the experimental drag data.

\section{Comparisons at Supersonic Conditions}

Four turbulence models, the equilibrium model of Baldwin-Lomax with the Degani-Schiff modifications, the one-equation Baldwin-Barth model, the one-equation Spalart-Allmaras model and a preliminary version of the 
Gatski/Speziale k- $\omega$ model, were used to perform runs for the M2.4-7A geometry at a $\mathrm{M}=2.48, \mathrm{Re}_{\mathrm{ft}}=5.26 \times 10^{6}$, and at two angles-of-attack, -1 and 2 degrees, representative of near minimum drag and cruise conditions, respectively. In this investigation, it is assumed that the entire boundary layer flow is turbulent, and is compared to free-transition, fixed-transition, and corrected-to-fully-turbulent experimental data.

The drag polar is shown in Figure 34. This figure shows the drag polar for two experimental conditions (fixed and free transition) and the four different turbulence models at Reynolds number per foot $=5.26$ million and Mach 2.48. There is also one point on each of the enlarged figures showing an experimental value corrected to the fully turbulent condition. Note the lower drag of the free transition data, indicating the presence of significant laminar flow. Also, note that the fixed and free transition experimental data bracket the fully turbulent computational results, indicating the presence of trip drag in the fixed transition experimental data. As the figure shows, SpalartAllmaras agrees the best with the corrected experimental data near minimum drag, and Baldwin-Barth agrees the best near cruise, with Spalart-Allmaras over predicting the drag by only 2 counts. In general, there is less difference in predicted drag between turbulence models here than in the transonic case previously shown.

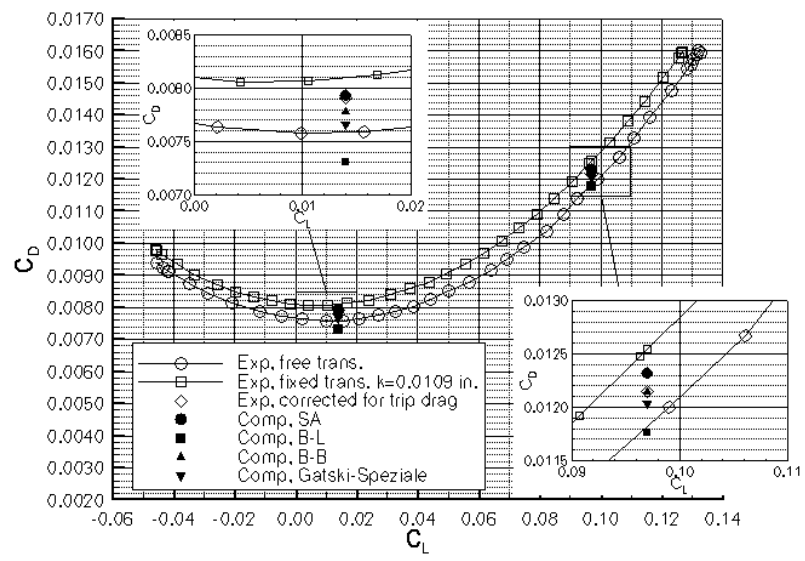

Figure 34. Drag Polar for the M2.4-7A configuration at $M=2.48, R_{\mathrm{ft}}=5.26 \times 10^{6}$.

Another result, shown in Figure 35, indicates that at $\alpha=-1.0$ deg (near minimum drag), all of the turbulence models predict the same lift, which is in between the free and fixed transition experimental data, as expected. At $\alpha=2.0$ deg (near cruise), all of the turbulence models again predict the same lift, but lower than both the experimental values. 


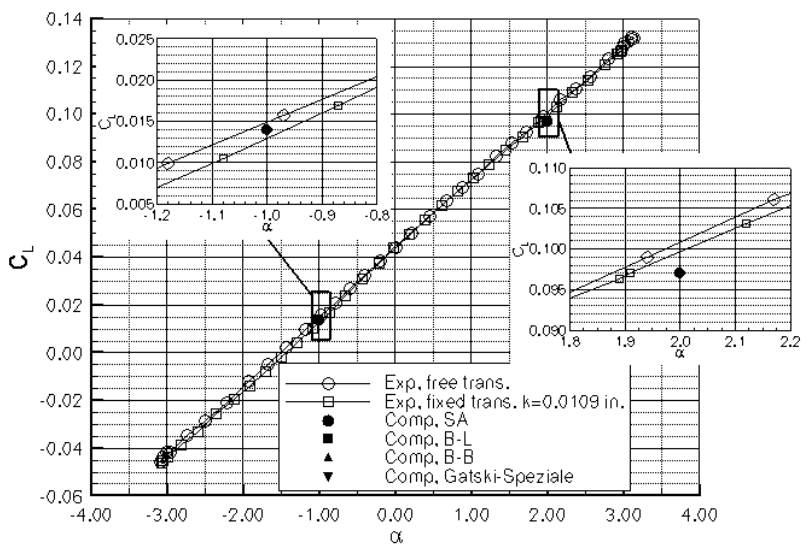

Figure 35. Lift Curve for the M2.4-7A configuration at $M=2.48, R_{\mathrm{ft}}=5.26 \times 10^{6}$.

The pitching moment curves, shown in Figure 36, show that all of the turbulence models predict the same pitching moment values at both $\alpha=-1.0$ and $2.0 \mathrm{deg}$. A slight rotation seen in the $\mathrm{C}_{\mathrm{m}} / \mathrm{C}_{\mathrm{L}}$ curve is consistent with a flexible model (experiment) versus a rigid model (CFD).

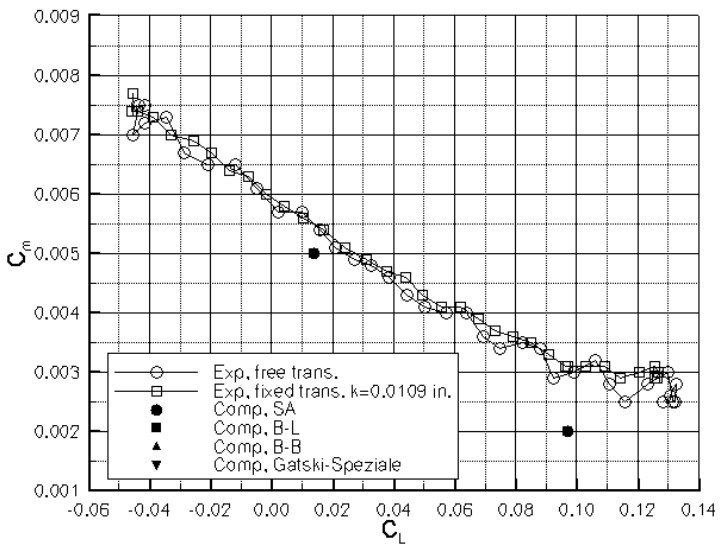

Figure 36. Pitching Moment Curve for the M2.4-7A configuration at $M=2.48, \mathrm{Re}_{\mathrm{ft}}=5.26 \times 10^{6}$.

\section{Conclusion}

Multiple turbulence models have been evaluated for transonic and supersonic flow conditions for realistic supersonic transport configurations using the thin-layer, upwind, Navier-Stokes flow solver known as CFL3D. The turbulence model study showed that the computed forces, moments and pressures compared reasonably well with the experimental data, with the B-L and B-B models showing the best agreement for the transonic study and the S-A model showing the best agreement for the supersonic study. The sensitivity to the turbulence model was larger in the transonic case than the supersonic case. 


\section{References}

1

Wilhite, A. W., and Shaw, R. J., “An Overview of NASA's High-Speed Research Program,” 20th ICAS Congress, Paper 112, August 2000.

2 Nelson, C.P., "Effects of Wing Planform on HSCT Off-Design Aerodynamics,” AIAA Paper 92-2629, June 1992.

3 Thomas, J., Krist, S., and Anderson, W., "Navier-Stokes Computations of Vortical Flows Over Low-Aspect-Ratio Wings," AIAA Journal, Vol. 28, No. 2, 1990, pp. 205-212.

4 Baldwin, B., and Lomax, H., "Thin Layer Approximation and Algebraic Model for Separated Turbulent Flow," AIAA 78-257, 1978.

5 Degani, D., Schiff, L.B., and Levy, Y., "Physical Considerations Governing Computation of Turbulent Flows Over Bodies at Large Incidence," AIAA Paper 90-0096, AIAA 28th Aerospace Sciences Meeting, Jan. 1990.

6 Baldwin, B., and Barth, T., "A One-Equation Turbulent Transport Model for High Reynolds Number Wall-Bounded Flows," NASA TM-102847, 1990.

7 Spalart, P., and Allmaras, S., "A One-Equation Turbulence Model for Aerodynamic Flows," AIAA 92-0439, 1992.

8 Menter, F.R., "Two-Equation Eddy-Viscosity Turbulence Models for Engineering Applications," AIAA Journal, Vol. 32, No. 8, pp. 1598-1605, 1994.

9 Abid, R., Rumsey, C., and Gatski, T., "Prediction of Nonequilibrium Turbulent Flows with Explicit Algebraic Stress Models," AIAA Journal, Vol. 33, No. 11, pp.2026-2031, November 1995.

10 Gloss, B. B.: "Current Status and Some Future Test Directions for the US National Transonic Facility," Wind Tunnels and Wind Tunnel Test Techniques, R. Aeronaut. Soc., 1992, pp. 3.1-3.7.

11 Igoe, W.B.: "Analysis of Fluctuating Static Pressure Measurements in the National Transonic Facility," NASA TP-3475, March 1996.

12 Bobbitt, C.W., Hemsch, M.J., and Everhart, J.L.: "NTF Characterization Status,” AIAA Paper 2001-755, January 2001.

13 Fuller, D.E.: "Guide for Users of the National Transonic Facility," NASA TM-83124, 1981.

14 Owens, L.R., and Wahls, R.A.: "Reynolds Number Effects on a Supersonic Transport at Subsonic, High-Lift Conditions," AIAA Paper 2001-0911, January 2001.

15 Wahls, R.A., Owens, L.R., and Rivers, S.M.B.: "Reynolds Number Effects on a Supersonic Transport at Transonic Conditions," AIAA Paper 2001-0912, January 2001.

16 Owens, L.R., Wahls, R.A., Elzey, M.B., and Hamner, M.P.: "Reynolds Number Effects on the Stability \& Control Characteristics of a Supersonic Transport," AIAA Paper 2002-0417, January 2002.

17 Owens, L.R.; Wahls, R.A.; and Rivers, S.M.: "Off-Design Reynolds Number Effects for a Supersonic Transport," Journal of Aircraft, vol. 42, no. 6, pp. 1427-1441, November-December 2005.

18 Owens, L.R.; Wahls, R.A.; Elzey, M.B.; and Hamner, M.P.: "Reynolds Number Effects on the Stability \& Control Characteristics of Supersonic Transports," Journal of Aircraft, vol. 44, no. 1, pp. 134-143, January-February 2007.

19 Roe, P., "Approximate Riemann Solvers, Parameter Vectors, and Difference Schemes," Journal of Computational Physics, Vol. 43, pp. 357-372, 1981.

20 Rivers, Melissa B.; and Wahls, Richard A.: "Turbulence Model Comparisons for a High-Speed Aircraft. NASA TP1999-209540, December 1999. 